\title{
Advances in the management of oesophageal motility disorders in the era of high-resolution manometry: a focus on achalasia syndromes
}

\begin{abstract}
Peter J. Kahrilas ${ }^{1}$, Albert J. Bredenoord², Mark Fox ${ }^{3}$, C. Prakash Gyawali ${ }^{4}$, Sabine Roman ${ }^{5}$, André J.P.M. Smout ${ }^{2}$ and John E. Pandolfino ${ }^{1}$; on behalf of the International Working Group for Disorders of Gastrointestinal Motility and Function
\end{abstract}

Abstract | High-resolution manometry (HRM) and new analysis algorithms, summarized in the Chicago Classification, have led to a restructured classification of oesophageal motility disorders. This advance has led to increased detection of clinically relevant disorders, in particular achalasia. It has become apparent that the cardinal feature of achalasia - impaired lower oesophageal sphincter (LES) relaxation - can occur in several disease phenotypes: without peristalsis (type l), with pan-oesophageal pressurization (type II), with premature (spastic) distal oesophageal contractions (type III), or with preserved peristalsis (outlet obstruction). Furthermore, no manometric pattern is perfectly sensitive or specific for achalasia caused by a myenteric plexopathy, and there is no biomarker for this pathology. Consequently, physiological testing reveals other syndromes not meeting achalasia criteria that also benefit from therapies formerly reserved for achalasia. These findings have become particularly relevant with the development of a minimally invasive technique for performing a long oesophageal myotomy, the per-oral endoscopic myotomy (POEM). Optimal management is to render treatment in a phenotype-specific manner; that is, POEM calibrated to patient-specific physiology for spastic achalasia and the spastic disorders, and more conservative strategies such as pneumatic dilation for the disorders limited to the LES. This Consensus Statement examines the effect of HRM on our understanding of oesophageal motility disorders, with a focus on the diagnosis, epidemiology and management of achalasia and achalasia-like syndromes.

High-resolution manometry (HRM), along with the analysis algorithms characterized in the Chicago Classification (CC) first proposed in 2008, have led to a major restructuring of the classification of oesophageal motility disorders. The inherently quantitative output of HRM devices fuelled enthusiastic expectation among motility experts that these advances would add a level of precision to the diagnosis of oesophageal motility disorders that was not previously possible. Nowhere was this advance more evident than in our concept of achalasia, now differentiated into subtypes as a direct result of HRM. Coincident with the assimilation of HRM into clinical practice was the development of a major therapeutic intervention for the management of oesophageal motility disorders, per-oral endoscopic myotomy
(POEM). Not only does the POEM procedure provide a therapeutic option for myotomy with reduced morbidity relative to laparoscopic or open myotomy, but it also enables a calibrated intervention that is customized to patient-specific physiology. Together, these developments fostered an increasing emphasis on targeting therapy to specific aspects of oesophageal dysfunction, as measured by physiological testing, rather than discrete diagnoses. Again, nowhere is this evolution more evident than in our strategies for managing achalasia. This Consensus Statement examines the effect of HRM on our current understanding of oesophageal motility disorders with a focus on how this technology has affected the diagnosis, epidemiology and management of achalasia and achalasia-like syndromes (BOX 1). 


\author{
Author addresses \\ ${ }^{1}$ Northwestern University, Feinberg School of Medicine, \\ Department of Medicine, 676 St Clair Street, 14th floor, \\ Chicago, Illinois 60611-2951, USA. \\ ${ }^{2}$ Academic Medical Centre, Department of \\ Gastroenterology and Hepatology, Meibergdreef 9, \\ 1105 AZ Amsterdam, The Netherlands. \\ ${ }^{3}$ Abdominal Center: Gastroenterology, St. Claraspital, Basel, \\ Switzerland and Clinic for Gastroenterology \& Hepatology, \\ University Hospital Zürich, Zürich, Switzerland. \\ ${ }^{4}$ Washington University, Division of Gastroenterology, \\ 660 S. Euclid Ave, Campus BOX 8124, St. Louis, \\ Missouri 63110, USA. \\ ${ }^{5}$ Digestive Physiology, Hospices Civils de Lyon \\ and Lyon I university Edouard Herriot Hospital, Pavillon L, \\ 5 place d'Arsonval, 69437 Lyon cedex 03, France.
}

\section{Methods}

The core HRM steering committee (P.J.K., A.J.B, M.F., C.P.G., S.R., A.J.P.M.S. and J.E.P.) was appointed by the International Working Group for Disorders of Gastrointestinal Motility and Function (http://www. idigest.ch/) to oversee the drafting and updating of the CC of oesophageal motility disorders. The first major version of the CC was published in 2009 after the inaugural meeting of the International HRM Working Group in San Diego, USA, in 2008. The next major update followed from a meeting of the International HRM Working Group in Ascona, Switzerland, in 2011 and was endorsed by numerous international motility and gastroenterology societies. An expanded International HRM Working Group met in Chicago, USA, in conjunction with Digestive Disease Week 2014 to formulate the CC v3.0, which was then finalized at the 2015 meeting of the International Working Group for Disorders of Gastrointestinal Motility and Function in Ascona. Since the publication of CC v3.0 in 2015 (REF. 1), which was also endorsed by numerous international motility societies, the clinical application of HRM has increased rapidly, as have the number of relevant clinical and investigational publications. Consequently, as part of this series of Consensus Statements on gastrointestinal motility, the HRM steering committee performed focused literature searches to explore the effect of CC v3.0 on the management of oesophageal motility disorders. A draft manuscript was initially formulated by one of the authors (P.J.K.), which was then circulated among all steering committee members for extensive discussion and debate. Consensus on the final content of the manuscript was achieved through careful evaluation and discussion of the available literature.

\section{High-resolution manometry}

Oesophageal motility testing was revolutionized with the widespread adoption of HRM in the early 2000s. With HRM, intraluminal pressure recordings are obtained with multiple closely spaced pressure sensors such that there is negligible loss of pressure data between sensors ${ }^{2}$. Manometric data are most commonly viewed and analysed in the form of pressure topography (FIG. 1). Alternatively called isobaric contour plots or, in recognition of the individual who pioneered these, Clouse plots ${ }^{3,4}$, these colour plots use a coordinate system of time on the $\mathrm{x}$-axis, sensor position in the oesophagus on the $y$-axis, and pressure values represented by colour within that coordinate system. Hence, although not synonymous, HRM is a prerequisite for creating accurate pressure topography plots, and we will henceforth refer to the combined technology as HRM.

HRM is not a complementary technology to conventional manometry; rather, it is replacement technology that has rendered conventional oesophageal manometry obsolete. Although some practitioners resisted this evolution, HRM has become 'conventional manometry' and most newly trained gastroenterologists are completely unfamiliar with the line-tracing manometry format of old. HRM has several advantages over conventional manometry: it is easier to perform high-quality studies of uniform format; a single probe position encompasses the entire oesophagus, negating the need to repeatedly reposition it during the study; the data format lends itself to the development of standardized objective measures of peristaltic and sphincter function; the process of interpretation is more intuitive and more easily learned by trainees or new practitioners ${ }^{5,6}$; and it results in an increased detection of achalasia and other clinically relevant diagnoses among patients with dysphagia $^{7}$. Nonetheless, HRM is still a technique requiring special expertise and training to perform high-quality studies $^{8-10}$. HRM is also more expensive than conventional manometry, and invites overinterpretation in inexperienced hands. Whether the person performing the study is a nurse, technician or physician, they must be able to assess the technical adequacy of the study as they are doing it. This assessment requires that they have sufficient knowledge to determine proper catheter positioning, recognize common artefacts and recognize equipment malfunction.

\section{The Chicago Classification}

The CC is a method for interpreting HRM studies and classifying oesophageal motility disorders. This classification scheme has been a work in progress, most recently summarized in 2015 as CC v3.0 (REF. 1). The CC reflects the ongoing deliberations of the International HRM Working Group that first met in San Diego, USA, in 2008 to standardize the interpretation of oesophageal HRM.

Box 1 | Key high-resolution manometry advances

- Introduction of the Chicago Classification for disorders of oesophageal motility based on objective metrics derived from high-resolution oesophageal manometry

- Characterization of achalasia subtypes with distinct prognosis and treatment outcomes

- Establishing a hierarchy of motility disorders based on the likelihood that abnormal motility causes symptoms and/or impairs bolus transport

- Distinguishing distal oesophageal spasm from pan-oesophageal pressurization and rapid contractions by the measurement of distal latency 

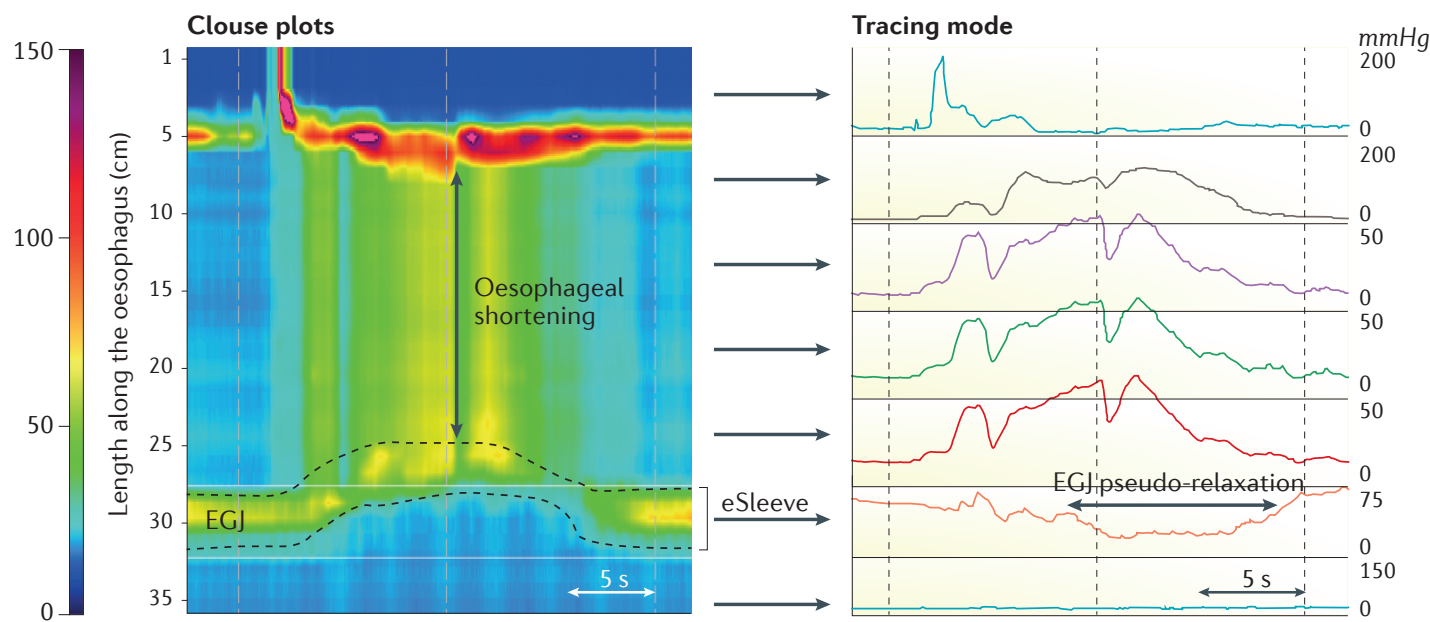

Figure 1 | Pseudorelaxation as a consequence of oesophageal shortening after a swallow in a patient with type II achalasia. The dotted lines on the high-resolution manometry (HRM) plot depict the path of the lower oesophageal sphincter, taking it above the span of the eSleeve (a 'virtual sleeve' placed at the oesophogastric junction) and thereby simulating relaxation (tracing panel).

Subsequently, the International HRM Working Group has expanded, both in personnel and in scope, addressing a broader range of physiological testing. The CC of oesophageal motility disorders v3.0 was finalized in Chicago, USA, during an International HRM Working Group meeting held in conjunction with Digestive Disease Week 2014. Addressing the goal of standardizing the interpretation of motility studies, this classification was subsequently endorsed by the American Neurogastroenterology and Motility Society, the European Society of Neurogastroenterology and Motility, and a number of other worldwide motility societies.

\section{Analysis metrics utilized in the CC}

The concept of the CC is to apply standardized metrics in the analysis of HRM studies to identify oesophageal motility disorders. Primarily, this approach applies to patients with non-obstructive dysphagia and/or oesophageal chest pain without a history of surgery affecting oesophageal function. Motility disorders are categorized as major in the CC if they are never found in normal healthy individuals or minor if there is overlap with observations in normal individuals. The scheme is based on an analysis of ten $5 \mathrm{ml}$ swallows performed in a supine or reclined position; however, reference ranges using the same metrics have also been published for studies conducted in the sitting position ${ }^{11}$. The CC is inherently a quantitative analysis, which has important technical ramifications because of manufacturerspecific performance characteristics. The device utilized in the investigational work for the development of the CC was the apparatus designed by Sierra Scientific (currently marketed by Medtronic, UK). Hence, the published normal values and discriminant characteristics of these metrics pertain to studies using Sierra devices and are different for studies using other equipment $^{12}$. This consideration is especially relevant with respect to measuring the completeness of oesophagogastric junction (EGJ) relaxation, key to the diagnosis of achalasia. Measurements of sphincter relaxation are notoriously susceptible to artefacts caused by oesophageal movement relative to the sensor during relaxation, the axial and longitudinal asymmetry of the sphincter, and dynamic fluctuations in OGJ pressure attributable to respiration and cardiac pulsation. The numerical values discussed herein pertain to the Sierra device.

Assessing lower oesophageal sphincter relaxation. The analysis of an HRM study begins with an assessment of the adequacy of deglutitive lower oesophageal sphincter (LES) relaxation, abnormality of which is a cardinal finding in achalasia. Several nuances of quantifying LES relaxation emerge in $\mathrm{HRM}^{1,8}$. First, other than in instances of hiatal hernia in which there is spatial separation of the LES and crural diaphragm, intraluminal sensors are measuring EGJ relaxation, not LES relaxation. Second, the sphincter moves proximally during swallowing, transient LES relaxations and spastic contractions as a consequence of oesophageal longitudinal muscle contraction; in extreme instances this proximal movement can be as much as $9 \mathrm{~cm}$. Consequently, a sensor positioned within the sphincter at rest can be distal to the sphincter after swallowing and subject to the artefact of 'pseudorelaxation' (REFS 13,14) (FIG. 1). Third, intraluminal EGJ pressure is affected by more than just the LES. At any one instance, EGJ pressure is the greatest of three possible contributing factors: LES pressure; pressure exerted by the crural diaphragm; or intrabolus pressure as the swallowed water becomes pressurized to traverse the EGJ ${ }^{15}$. These considerations led to the development of the HRM EGJ relaxation metric of integrated relaxation pressure (IRP) ${ }^{14}$. IRP is defined as the mean pressure during the $4 \mathrm{~s}$ of maximal deglutitive relaxation in the $10 \mathrm{~s}$ window beginning at upper oesophageal sphincter (UES) relaxation and referenced to gastric pressure. Contributing times to the IRP can be contiguous or non-contiguous when interrupted by diaphragmatic contraction. The IRP 

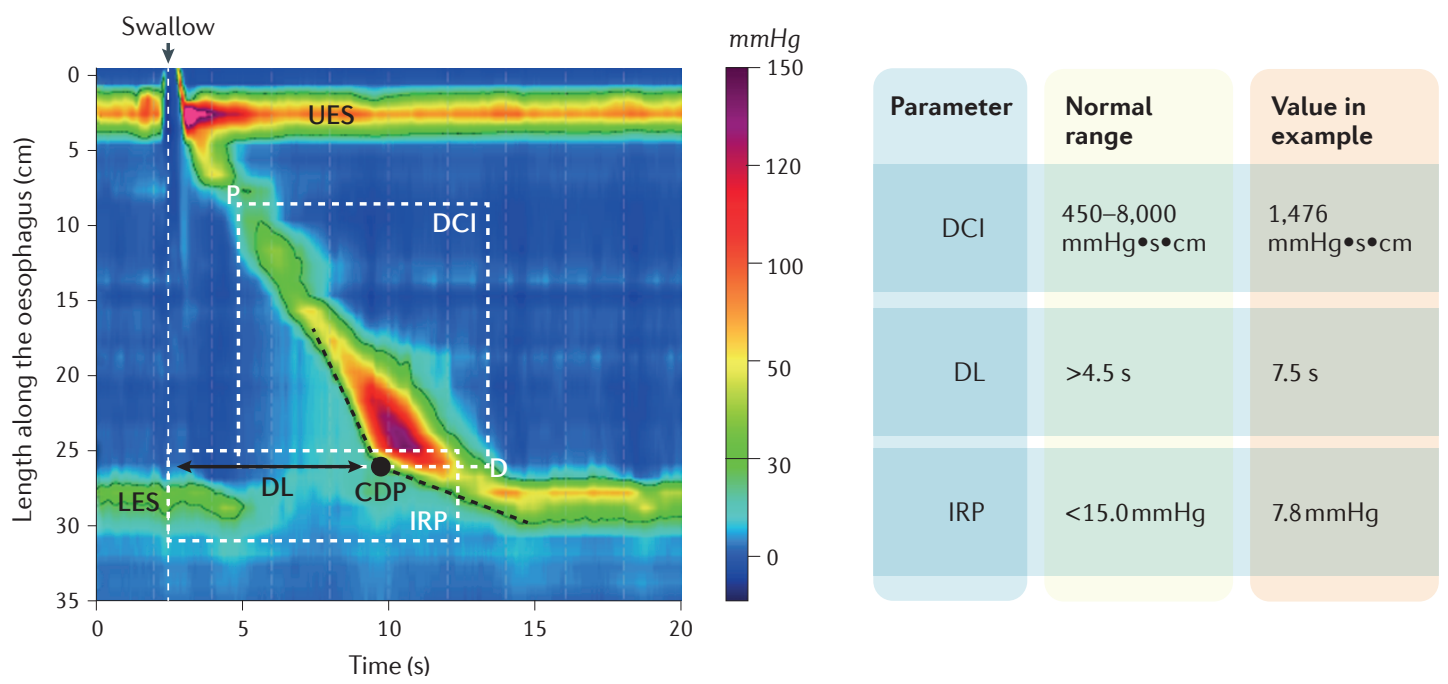

Figure 2 | Key metrics of pressure topography (Clouse) plots used to describe peristalsis in the Chicago

Classification. $P$ is the nadir pressure value, sometimes called the transition zone, separating the first two contractile segments. $D$ is the pressure minimum that separates the second two segments, both of which reside in the smooth muscle oesophagus, from the lower oesophageal sphincter (LES). The distal contractile integral (DCI) is a summation of the contractile amplitude in the span from $P$ to $D$ in units of $\mathrm{mmHg} \cdot \mathrm{s} \cdot \mathrm{cm}(1,476 \mathrm{mmHg} \cdot \mathrm{s} \cdot \mathrm{cm}$ in this example). The contractile deceleration point (CDP) indicating the transition from peristalsis to ampullary emptying is localized in the distal oesophagus by the intersection of the two black dotted tangent lines. Distal latency (DL) is measured from upper sphincter relaxation (vertical white dotted line) to the CDP. Oesophagogastric junction relaxation is summarized by the integrated relaxation pressure (IRP), which is calculated within the $10 \mathrm{~s}$ IRP window beginning with upper sphincter relaxation as the average eSleeve pressure during the $4 \mathrm{~s}$ of greatest relaxation ( $7.8 \mathrm{mmHg}$ in this example). The eSleeve is a 'virtual sleeve' placed at the oesophogastric junction. Normal values and those depicted in the example plot are indicated in the table. UES, upper oesophageal sphincter.

is expressed as a median value of the 10 test swallows with $15 \mathrm{mmHg}$ being the upper limit of normal ${ }^{1}$. An IRP $>15 \mathrm{mmHg}$ defines EGJ outflow obstruction (EGJOO). However, as with any metric, an IRP $>15 \mathrm{mmHg}$ is neither $100 \%$ sensitive nor $100 \%$ specific for clinically relevant EGJOO. In the initial description of this metric, which was applied to 400 patients (including 62 with achalasia) and 73 healthy individuals, the IRP cut-off of $15 \mathrm{mmHg}$ was found to be $98 \%$ sensitive and $96 \%$ specific for the detection of achalasia ${ }^{13}$.

Assessing peristalsis. After defining the adequacy of EGJ relaxation, the next step in the hierarchical analysis of an HRM study is to characterize peristalsis. The metrics used to identify the major motility disorders in CC v3.0 are the distal contractile integral (DCI) and the distal latency (FIG. 2). The DCI integrates the length, vigor and persistence of the distal oesophageal contraction from the pressure minima at the transition

Table 1 | Clinical achalasia syndromes within the CC v3.0

\begin{tabular}{|c|c|c|c|}
\hline Subtype & IRP > ULN? & $\begin{array}{l}\text { Oesophageal } \\
\text { contractility }\end{array}$ & Added criteria \\
\hline Type I & Yes & Absent contractility & None \\
\hline Type II & Yes & Absent peristalsis & $\begin{array}{l}\text { Pan-oesophageal pressurization } \\
\text { with } \geq 20 \% \text { of swallows }\end{array}$ \\
\hline Type III & Yes & $\begin{array}{l}\text { - Absent peristalsis } \\
\text { - Premature contractions } \\
\text { with } \geq 20 \% \text { of swallows }\end{array}$ & None \\
\hline
\end{tabular}

CC, Chicago Classification; IRP, integrated relaxation pressure; ULN, upper limit of normal zone to the EGJ. Conceptually, if the Clouse plot of distal oesophageal contraction is envisioned as a $3 \mathrm{D}$ solid, the 'footprint' of the solid is time (s) multiplied by length of the distal oesophageal segment $(\mathrm{cm})$ and the height of the solid is pressure. The DCI is the volume of that solid spanning from $20 \mathrm{mmHg}$ at the base to its peak(s) expressed as $\mathrm{mmHg} \cdot \mathrm{s} \cdot \mathrm{cm}$. The lower $20 \mathrm{mmHg}$ is excluded from the calculation to minimize the contribution of pressure artefacts that are unrelated to oesophageal contraction. The DCI is used to define hypercontractile swallows (DCI $>8,000 \mathrm{mmHg} \cdot \mathrm{s} \cdot \mathrm{cm}$ ), weak swallows (DCI $<450 \mathrm{mmHg} \cdot \mathrm{s} \cdot \mathrm{cm}$ ) and failed peristalsis (DCI $<100 \mathrm{mmHg} \cdot \mathrm{s} \cdot \mathrm{cm})$ (FIG. 2).

The other major abnormality of peristalsis is of premature contractions, defined by the distal latency. Physiologically, premature contractions imply dysfunction of the inhibitory neurons of the oesophageal myenteric plexus and are the defining characteristic of distal oesophageal spasm and type III achalasia in CC v3.0 (REF. 16). The distal latency is measured as the interval from UES relaxation to the contractile deceleration point $(\mathrm{CDP})$, the inflection point in the wave front velocity just proximal to the EGJ. ${ }^{15} \mathrm{~A}$ distal latency $<4.5 \mathrm{~s}$ defines a premature contraction. Hence, the CDP is a key landmark in the assessment of the contraction pattern. Propagation velocity slows at the CDP, demarcating the transition from peristalsis to ampullary emptying, which is mechanistically distinct from peristalsis. However, the CDP can be difficult to localize in instances of atypical peristaltic architecture or compartmentalized pressurization, leading to the stipulation of two further 
conditions: to overcome issues associated with atypical peristaltic architecture, the CDP must be localized to within $3 \mathrm{~cm}$ of the $\mathrm{LES}^{17}$; and in instances of compartmentalized pressurization, the CDP needs to be localized along an isobaric contour line of greater magnitude than the compartmentalized intrabolus pressure.

\section{Achalasia phenotypes}

Aside from objectifying the definition of impaired deglutitive EGJ relaxation and thereby improving the sensitivity of manometry for detecting achalasia, HRM has also established a subclassification of achalasia based on the associated pattern of contractility proximal to the sphincter ${ }^{18}$ (TABLE 1). A diagnosis of achalasia requires both impaired deglutitive EGJ relaxation and absent peristalsis ${ }^{19}$. However, absent peristalsis is not synonymous with absent pressurization or contractility.
In fact, both oesophageal pressurization and nonperistaltic contractility are quite common in achalasia (FIG. 3). In conventional manometry, such instances were often referred to as 'vigorous achalasia', although that term never had a clear definition and its use was discouraged in the pre-HRM oesophageal motor disorder classification scheme $\mathrm{e}^{20}$. A seminal observation in the early days of HRM was that absent peristalsis accompanying impaired EGJ relaxation can occur with three associated patterns of oesophageal contractility: negligible pressurization within the oesophagus, defining classical or type I achalasia; pan-oesophageal pressurization wherein contractions that do not occlude the lumen result in uniform pressurization within the oesophagus spanning from the UES to the LES, defining type II achalasia (achalasia with pressurization); or premature (short latency) spastic contractions within

\section{a Type I achalasia}

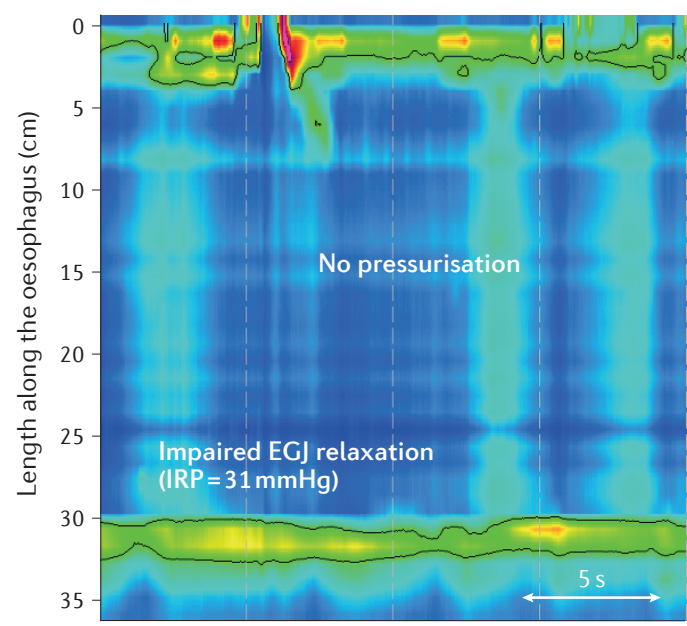

c Type III achalasia

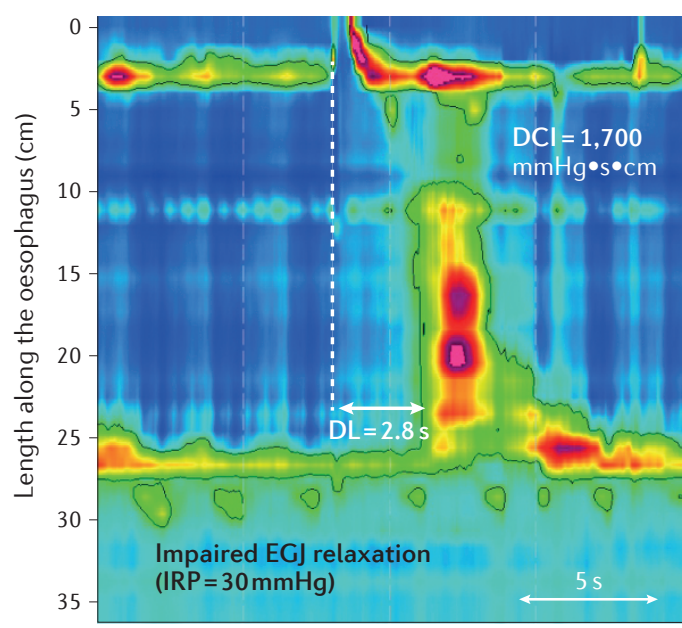

\section{b Type II achalasia}

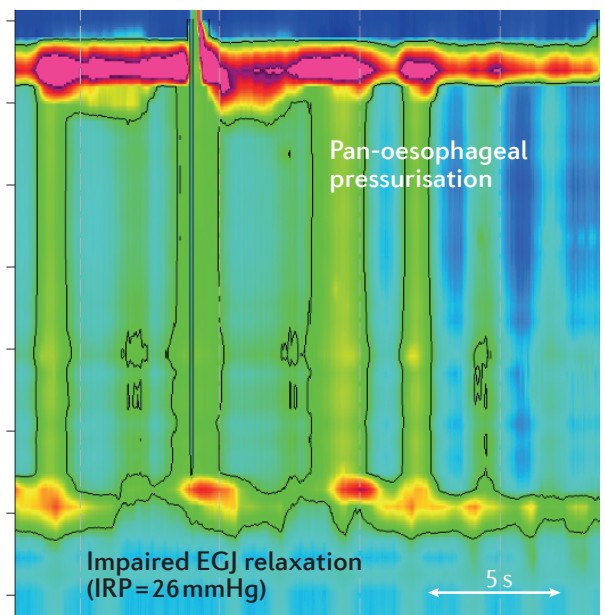

d EGJ outflow obstruction

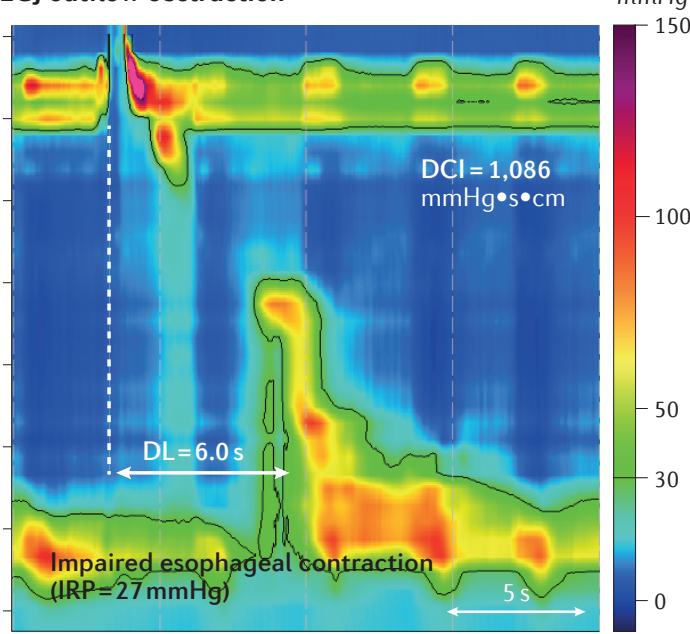

Figure 3 | High-resolution manometry of achalasia subtypes. a | According to the Chicago Classification v3.0, the criteria for classic achalasia (type I achalasia) are an integrated relaxation pressure (IRP) $\geq 15 \mathrm{mmHg}$ and absent peristalsis without marked pressurization or contractions. $\mathbf{b} \mid$ Achalasia with oesophageal pressurization (type II achalasia) has an IRP $\geq 15 \mathrm{mmHg}$ and at least $20 \%$ of swallows associated with pan-oesophageal pressurization to $>30 \mathrm{mmHg}$. c|Spastic achalasia (type III achalasia) has an IRP $\geq 15 \mathrm{mmHg}$ and a spastic contraction with $\geq 20 \%$ of test swallows ${ }^{20}$. d $\mid$ An example of oesophagogastric junction (EGJ) outflow obstruction treated as achalasia but not meeting diagnostic criteria for achalasia because of preserved fragments of peristalsis. Dashed white lines represent initial upper oesophageal sphincter relaxation $\mathrm{DL}$, distal latency. 
the distal oesophagus, defining type III, or spastic, achalasia ${ }^{19}$ (FIG. 3). In multiple reported HRM series from major centers worldwide, type II achalasia is the most common subtype ${ }^{18,21-23}$. Paradoxically, type II achalasia would often go undetected or misdiagnosed with conventional manometry because of LES pseudorelaxation during pan-oesophageal pressurization, or because panoesophageal pressurization was mistaken for a spastic contraction, resulting in an alternative diagnosis of distal oesophageal spasm.

\section{Achalasia syndromes beyond CC subtypes}

Classification schemes are important and the CC v3.0 has gone a long way in objectifying the diagnosis of achalasia. However, the fact that the CC has already gone through three iterations emphasizes that this classification is a work in progress and that no classification scheme will ever be perfect. After all, no biomarker of achalasia exists and although we recognize that in typical cases the underlying pathology is of a myenteric plexopathy ${ }^{24}$, the diagnosis is rarely, if ever, established by neuropathology. Rather, the diagnosis is established using physiological tests to demonstrate that symptomatic oesophageal dysfunction (potentially dysphagia, regurgitation, chest pain or heartburn) is occurring as a result of oesophageal outflow obstruction that cannot be attributed to a stricture, tumour, vascular structure, implanted device or infiltrating process ${ }^{19}$. Consequently, it is imperative to recognize two important limitations of CC v3.0 with respect to the diagnosis of achalasia: some patients have achalasia and an IRP $<15 \mathrm{mmHg}$; and there can be instances in which peristalsis is preserved (TABLE 2). Furthermore, the distinction between achalasia subtypes (especially type I and II) can be difficult because some cases can have features of more than one subtype and the disease evolves over a variable time span. When the disease develops slowly, there is a gradual transition from normal peristalsis and normal
EGJ relaxation to absent peristalsis and EGJOO; at intermediate time points in the development of the disease, these abnormalities might or might not achieve the requisite diagnostic threshold.

\section{Normal IRP achalasia}

A prerequisite for IRP to be $>15 \mathrm{mmHg}$ is that EGJ pressure is $>15 \mathrm{mmHg}$, which is not always the case in achalasia, particularly in type I disease (TABLE 2). This finding is explained partly because, in the absence of oesophageal pressurization, IRP becomes solely dependent on EGJ contractility, and partly because some patients with achalasia have a very low LES pressure, especially those with advanced disease. Historically, recognition of this limitation led some practitioners of conventional manometry to express LES relaxation as a percentage relaxation from baseline pressure rather than as a nadir pressure, but that approach ultimately fails in the opposite (more common) instance of patients with achalasia with high EGJ pressure wherein the percentage relaxation is 'normal' but the residual pressure is high. Another approach is to alter the IRP cut-off for defining type I achalasia. This method was proposed by Lin et al. ${ }^{25}$ on the basis of a classification and regression tree model that suggested that for type I achalasia the optimal IRP cut-off for EGJ relaxation was $10 \mathrm{mmHg}$. However, the International Working Group formulating CC v3.0 rejected that proposal, arguing that it would be too confusing. Rather, they suggested that the diagnosis of achalasia still be considered if there was a borderline median IRP with evidence of oesophageal pressurization. However, not even that criteria suffices, as evidenced by a study published in 2017 that reported extremely low IRP values $(3 \mathrm{mmHg}, 5 \mathrm{mmHg}$ ) in some patients with achalasia in whom impaired sphincter function was demonstrable using functional luminal imaging probe (FLIP) technology and stasis on the barium oesophagram ${ }^{26}$.

Table 2 | Achalasia syndromes beyond the CC v3.0

\begin{tabular}{|c|c|c|c|}
\hline CC v3.0 diagnosis & IRP $>$ ULN? & Oesophageal contractility & Notes \\
\hline $\begin{array}{l}\text { Oesophagogastric } \\
\text { junction outflow } \\
\text { obstruction }\end{array}$ & Yes & $\begin{array}{l}\text { Sufficient peristalsis to exclude } \\
\text { type I, II or III achalasia }\end{array}$ & $\begin{array}{l}\text { - Heterogeneous group } \\
\text { - Early or incomplete achalasia } \\
\text { - Can resolve spontaneously } \\
\text { - Recording artefacts }\end{array}$ \\
\hline Absent contractility & No & Absent contractility & $\begin{array}{l}\text { - Can be achalasia } \\
\text { - Abnormal FLIP distensibility index } \\
\text { supports achalasia } \\
\text { - Oesophageal pressurization with } \\
\text { swallows or MRS supports achalasia }\end{array}$ \\
\hline Distal oesophageal spasm & Yes or no & $\begin{array}{l}\geq 20 \% \text { premature contractions } \\
\text { (DL<4.5s) }\end{array}$ & Might be spastic achalasia \\
\hline Jackhammer & Yes or no & $\begin{array}{l}\geq 20 \% \text { of swallows with } \mathrm{DCl} \\
>8,000 \mathrm{mmHg} \cdot \mathrm{s} \cdot \mathrm{cm}\end{array}$ & $\begin{array}{l}\text { Might be spastic achalasia if } \mathrm{DL}<4.5 \mathrm{~s} \\
\text { with } \geq 20 \% \text { swallows }\end{array}$ \\
\hline Opioid effect (not in CC) & Yes & $\begin{array}{l}\text { Normal, hypercontractile or } \\
\text { premature }\end{array}$ & $\begin{array}{l}\text { Can mimic EGJOO, type III achalasia, } \\
\text { DES or jackhammer }\end{array}$ \\
\hline $\begin{array}{l}\text { Mechanical obstruction } \\
\text { (not in CC) }\end{array}$ & Yes & Absent, normal or hypercontractile & $\begin{array}{l}\text { EUS, CT or MRI of the EGJ might } \\
\text { clarify the aetiology }\end{array}$ \\
\hline
\end{tabular}

CC, Chicago Classification; DCl, distal contractile integral; DES, distal oesophageal spasm; DL, distal latency; EGJ, oesophagogastric junction; EGJOO, EGJ outflow obstruction; EUS, endoscopic ultrasonography; FLIP, functional luminal imaging probe; IRP, integrated relaxation pressure; MRS, multiple repetitive swallows; ULN, upper limit of normal. 

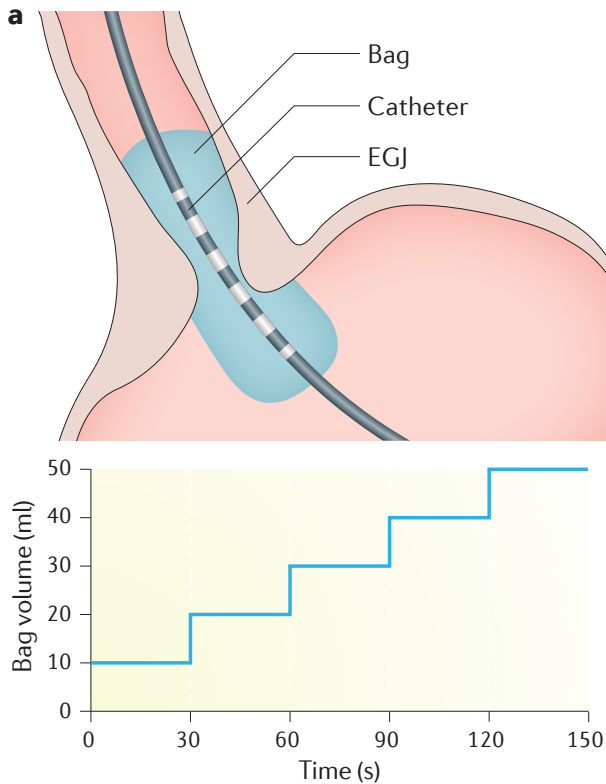

b

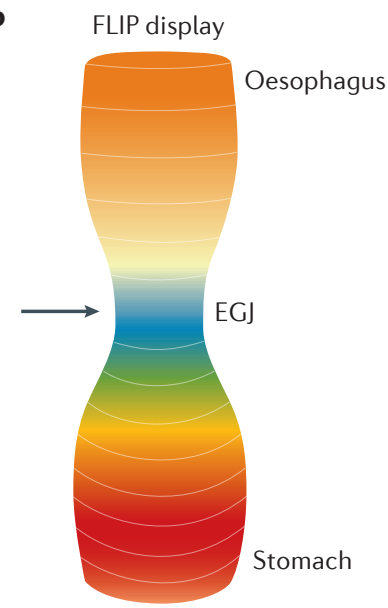

- Bag volume $=50 \mathrm{ml}$ - $\operatorname{CSA}(\mathrm{min})=58 \mathrm{~mm}^{2}$ - Pressure $=45.2 \mathrm{mmHg}$ - Distensibility $1.3 \mathrm{~mm}^{2}$ per $\mathrm{mmHg}$
Figure 4 | Functional luminal imaging probe study demonstrating decreased oesophagogastric junction distensibility. Oesophagogastric junction (EGJ) distensibility in this patient with achalasia is $1.3 \mathrm{~mm}^{2}$ per $\mathrm{mmHg}$. The optimal threshold for detecting achalasia is $<2.8 \mathrm{~mm}^{2}$ per $\mathrm{mmHg}$. a | The positioning of the functional luminal imaging probe (FLIP) device at the EGJ along with the stepwise distension protocol. $\mathbf{b}$ |The corresponding FLIP display and calculated values for cross-sectional area, pressure and EGJ distensibility index are shown. CSA, cross-sectional area; FLIP, functional lumen impedance planimetry. half of the 30 patients studied exhibited instances of either intact peristaltic contractions or remnants of distal peristalsis in their HRM study after treatment.

Peristalsis recovery after treatment. Recovery of peristalsis after Heller myotomy emphasizes the heterogeneity of achalasia pathogenesis. Although distal oesophageal myenteric plexus degeneration is a pathological feature of achalasia, the pattern and intensity of inflammation are variable ${ }^{24}$. Recovery of distal peristalsis after myotomy suggests that neuronal dysfunction limited to the LES might dominate in some patients with achalasia. Instances of short-segment achalasia were reported before the advent of $\mathrm{HRM}^{35}$, and in these cases the absent peristalsis observed before treatment was a consequence of EGJ obstruction. This phenomenon was demonstrated by Mittal et al. ${ }^{36}$ in cats by placing ligatures around the LES, which resulted in failed peristalsis with increasing degrees of outflow obstruction. In that model, peristalsis promptly returns after ligature removal ${ }^{37}$. In humans, laparoscopic adjustable gastric band placement as a treatment for obesity can represent an analogous model of EGJ obstruction. Manometric features of achalasia have been observed after laparoscopic adjustable gastric band placement, and peristalsis has been restored after band deflation or removal in some cases ${ }^{38,39}$.

Partial recovery of peristalsis after myotomy might also be indicative of the progressive stages of achalasia pathogenesis. Support for this hypothesis is found in a classic study of achalasia neuropathology, with the observation that in vigorous achalasia (preserved oesophageal contractility) myenteric plexus inflammation was associated with a normal number of ganglion cells without neural fibrosis, whereas classic achalasia was associated with neural fibrosis and few, if any, ganglion cells ${ }^{40}$. The authors concluded that inflammation was an early stage in the disease, eventually followed by aganglionosis and fibrosis. Such progression was also suggested in a study published in 2016 that showed greater ganglion cell loss in type I achalasia than in type II achalasia, supporting the notion that type II is an earlier stage of the disease ${ }^{41}$. Within this concept, recovery of peristalsis after myotomy might indicate an inflamed, but surviving, distal oesophageal myenteric plexus, whereas lack of recovery might indicate progression to aganglionosis. In support of this hypothesis, post-myotomy peristalsis in the Roman et al. study was usually characterized as weak with low DCI values ${ }^{34}$. Along the same lines, FLIP detected non-occluding or occluding contractions in 10 of 10 patients with type III achalasia, two-thirds of the 26 patients with type II achalasia tested and one-third of the 15 patients with type I achalasia ${ }^{42}$.

EGJOO. In addition to the three subtypes of achalasia, CC v3.0 recognizes EGJOO as another potential phenotype of achalasia (FIG. 3d; TABLE 2). In this entity, IRP is $>15 \mathrm{mmHg}$, but there is sufficient evidence of peristalsis such that criteria for type I, type II or type III achalasia are not met. From the outset, those with EGJOO were recognized to be a heterogeneous group of patients, only some of whom benefited from achalasia treatments ${ }^{43}$. 


\section{CONSENSUS STATEMENT}
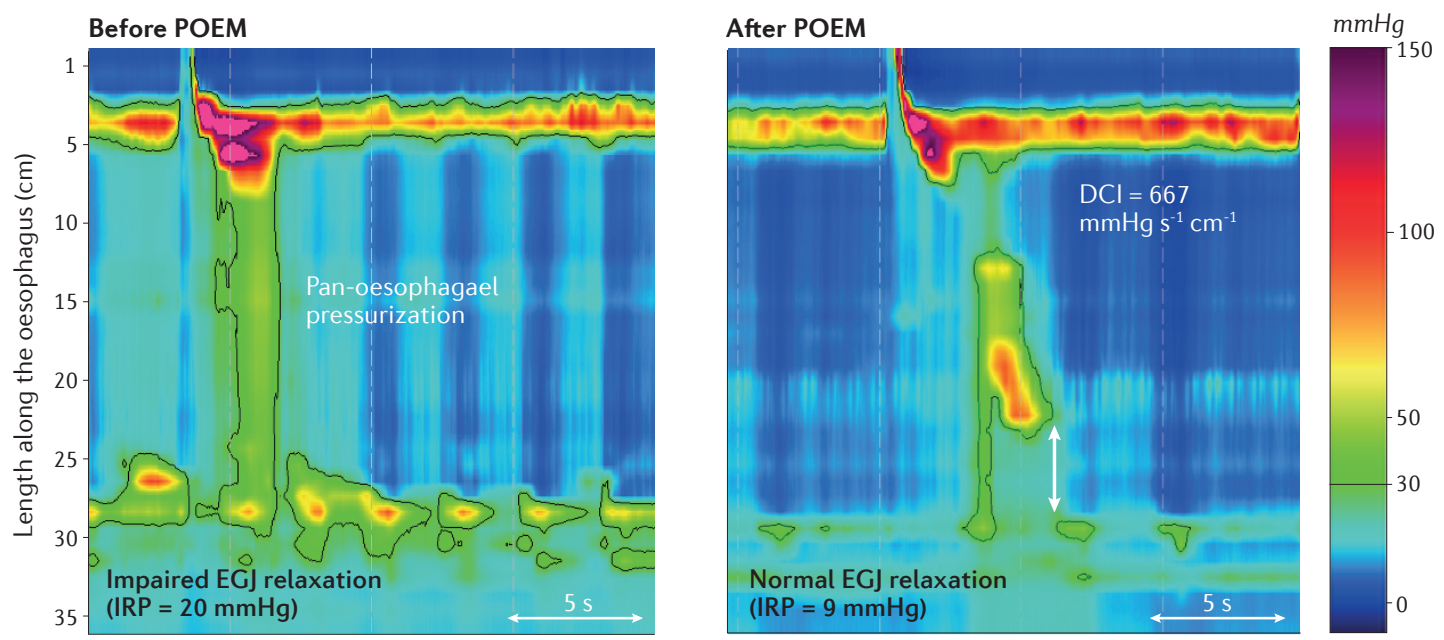

Figure 5 | High-resolution manometry studies performed before and after a POEM procedure in a patient with type II achalasia. Note the fragment of peristalsis proximal to the myotomy (double-headed arrow, extends $5 \mathrm{~cm}$ proximal to the EGJ) after per-oral endoscopic myotomy (POEM) that was not evident before myotomy. $\mathrm{DCl}$, distal contractile integral; EGJ, oesophagogastric junction; IRP, integrated relaxation pressure.

Consequently, EGJOO always requires more intense clinical evaluation (for example, with endoscopic ultrasonography, FLIP and CT, among others) to clarify its aetiology. Potential aetiologies include incompletely expressed or early achalasia, oesophageal wall stiffness from an infiltrative disease or cancer, vascular obstruction, sliding or para-oesophageal hiatal hernia, abdominal obesity or the effects of opiates ${ }^{44}$. Similar findings are found also in patients with dysphagia after restrictive, antireflux and bariatric procedures ${ }^{45-47}$. However, two series published in the past few years found that many patients with EGJOO were minimally symptomatic or asymptomatic, that in $20-40 \%$ of cases the 'disorder' resolved spontaneously, and that only $12-40 \%$ were treated (conservatively) as having achalasia ${ }^{48,49}$. To increase the specificity of an elevated IRP with preserved peristalsis for the diagnosis of EGJOO, provocative maneuvers or adjunctive studies, such as a rapid drink challenge or solid test meal, can be applied ${ }^{50,31}$. Increasing the volume and/or viscosity of the bolus increases oesophageal pressurization and, therefore, IRP in the presence of clinically significant EGJOO. The clinical utility of this approach was demonstrated in a prospective study of patients with persistent symptoms after fundoplication surgery. The diagnostic yield of EGJOO in this group of patients was increased by inclusion of solids in HRM studies, and symptoms improved after pneumatic dilation ${ }^{46}$.

\section{Achalasia epidemiology re-examined}

A common observation among early adopters of HRM was increased detection of achalasia, leading to the suspicion that the disease was more common than previously reported. Several factors make it difficult to obtain accurate figures on the incidence and prevalence of achalasia. Importantly, in the absence of a disease biomarker, achalasia detection depends on physiological testing, which has never been done on an adequately sized population-based sample to get meaningful data on achalasia. Consequently, available estimates, reporting annual incidence and prevalence values of about 1 per 100,000 and 10 per 100,000 , respectively ${ }^{51}$, are based on the assumption that all cases are detected. This assumption is obviously not true. One immediate inconsistency is the 1:10 incidence to prevalence ratio. Achalasia is not a fatal disease and there is no reason to think that affected individuals live with the disease for a mean of only 10 years (as would be the case if that ratio were correct). Furthermore, there is the major issue that achalasia in many patients is undetected throughout the life course or is misdiagnosed. It is in this context that the effect of the widespread adoption of HRM on estimates of incidence and prevalence needs to be considered.

An accurate estimate of the incidence and prevalence of achalasia, as defined by HRM, would require a very large population-based HRM study. That not being practical, one alternative approach would be to study a region with a captive population because of reimbursement considerations for manometry. Such a report, partially based on HRM, was published in 2017 on data from South Australia, a state in which all manometry studies are performed at three expert centers and detailed databases are maintained ${ }^{52}$. Their analysis concluded that the adult incidence of achalasia was 2.3-2.8 per 100,000 for the decade ending in 2013. Another alternative methodology would be to study a population in the vicinity of a high-visibility, well-established practice that has been doing high-quality HRM studies since the introduction of the technology. The group pioneering the development of the CC reported such a study in 2017 (REF. 53). That report analysed the incidence and prevalence of achalasia over a 10-year period for the 250,000 adults living in the vicinity of Northwestern Memorial Hospital (NMH), Chicago, USA, as defined by their home address zip codes. This approach still yields a systematic underestimate because it assumed that every incident achalasia case in the NMH neighbourhood was diagnosed, 
Table 3 | Percentage of good treatment outcomes among achalasia subtypes

\begin{tabular}{|c|c|c|c|c|c|}
\hline Study & $\begin{array}{l}\text { Patients } \\
\text { included }\end{array}$ & Treatment & $\begin{array}{l}\text { Type I } \\
\text { achalasia } \\
\text { (n) }\end{array}$ & $\begin{array}{l}\text { Type II } \\
\text { achalasia } \\
\text { (n) }\end{array}$ & $\begin{array}{l}\text { Type III } \\
\text { achalasia } \\
\text { (n) }\end{array}$ \\
\hline $\begin{array}{l}\text { Pandolfino } \\
\text { et al. }(2008)^{18}\end{array}$ & 99 & $\begin{array}{l}\text { - PD } \\
\text { - LHM } \\
\text { - Botulinum } \\
\text { toxin type A }\end{array}$ & $56 \%(21)$ & $96 \%(49)$ & $29 \%(29)$ \\
\hline $\begin{array}{l}\text { Salvador } \\
\text { et al. }(2010)^{21}\end{array}$ & 246 & LHM & $85 \%$ (96) & $95 \%(127)$ & $69 \%(23)$ \\
\hline $\begin{array}{l}\text { Pratap et al. } \\
(2011)^{22}\end{array}$ & 51 & PD & $63 \%(24)$ & $90 \%(24)$ & $33 \%(3)$ \\
\hline $\begin{array}{l}\text { Rohof et al. } \\
(2013)^{23}\end{array}$ & 176 & $\begin{array}{l}\text { RCT of PD } \\
\text { and LHM }\end{array}$ & $\begin{array}{l}\text { PD: } 86 \% \\
\text { - LHM: } 81 \% \\
\text { (44) }\end{array}$ & $\begin{array}{l}\text { - PD: } 100 \% \\
\text { - LHM: } 95 \% \\
\text { (114) }\end{array}$ & $\begin{array}{l}\text { - PD: } 40 \% \\
\text { - LHM: } 86 \% \\
\text { (18) }\end{array}$ \\
\hline
\end{tabular}

Definitions of a good outcome are variable among the reports, but type II patients consistently achieved the best outcomes and type III the worst. PD, pneumatic dilation; LHM, laparoscopic Heller myotomy; RCT, randomized controlled trial.

and that every incident case was diagnosed and managed at NMH. Neither of these assumptions was true because the fraction of achalasia cases that go undetected is unknown, and, although NMH does command a large local market share, the reality of competing insurance networks, the uninsured and the underinsured in the USA make it a virtual certainty that a substantial number of patients were managed elsewhere. Nonetheless, the estimated incidence of achalasia averaged 2.92 per 100,000 during a 10-year period and the prevalence progressively increased from 15.64 to 32.58 per 100,000 over the same period, with no plateau evident. The age of diagnosis was spread evenly among the adult decades of life with a mean age of 56 years. Consequently, the rising prevalence is consistent with the hypothesis that the low-mortality nature of achalasia led the Chicago group to accumulate cases over time ${ }^{54}$. Projecting those prevalence estimates forward, and assuming an average life expectance of 82 years in that part of Chicago, achalasia prevalence is anticipated to stabilize at a value about 26 times the incidence or, in this case, at 76 per 100,000 population, approaching $0.1 \%$. At this estimated prevalence, achalasia is still a rare disease, but is substantially more prevalent than the prior estimates of 10 per 100,000 .

\section{Phenotype-directed treatment}

As described in TABLE 1 and TABLE 2, all phenotypes of achalasia share the common element of EGJOO, but the associated pattern of oesophageal contractility varies from absent contractility at one extreme to spastic contractions at the other. One of the original observations with the description of achalasia phenotypes was that treatment outcome was dependent on phenotype, with outcomes being best in type II and probably worst in type III $^{18}$. Those observations have subsequently been confirmed by a number of other studies ${ }^{21-23}$ (TABLE 3).

No current treatment halts the immunologically driven plexopathy that drives development of idiopathic achalasia ${ }^{24}$. Rather, treatments aim to alleviate the hallmark abnormality of the disease, oesophageal outflow obstruction. Going forward, it is time to compare therapies within disease subtypes, be that achalasia types I, II, or III, or the achalasia syndromes detailed in TABLE 2, as each subtype has unique treatment considerations and each could well have a unique optimal management strategy. Relevant features to consider are deglutitive sphincter dysfunction, mechanical oesophageal outflow obstruction, obstructive contractility of the distal oesophagus, and the severity of oesophageal dilatation with sigmoid deformation.

\section{LHM and pneumatic dilation}

Until the past 5 years, the main durable treatment options for achalasia were laparoscopic Heller myotomy (LHM) or pneumatic dilation. Pneumatic dilation is performed with a noncompliant, cylindrical balloon ( $30 \mathrm{~mm}, 35 \mathrm{~mm}$ or $40 \mathrm{~mm}$ in diameter) positioned across the LES with fluoroscopic guidance and inflated using a handheld manometer. A study published in 2015 described a modification of this technique, with the introduction of a $30 \mathrm{~mm}$ diameter hydraulic dilator used in conjunction with FLIP technology and not requiring concomitant fluoroscopy $\mathrm{y}^{55}$. The standard surgical alternative to pneumatic dilation is a LHM, in which the circular muscle fibres of the LES are surgically divided. Because of the propensity of this procedure to cause reflux, LHM is usually combined with a partial fundoplication. An extensive literature has compared LHM with pneumatic dilation ${ }^{51}$, culminating in a multicenter European randomized controlled trial comparing the two for the treatment of achalasia, which concluded that both approaches were $~ 90 \%$ effective with no statistically significant difference in therapeutic success between them ${ }^{56,57}$. However, that trial (and all preceding trials) did not consider achalasia subtypes in their design or in their assessment of treatment efficacy. Both the data in TABLE 3 and a subsequent reassessment of the European achalasia trial ${ }^{23}$ suggest that achalasia subtypes are of great relevance in terms of treatment effectiveness. Indeed, in the European achalasia trial, the efficacy of pneumatic dilation for treating type II achalasia was $100 \%$, significantly better than LHM $(93 \%, P=0.03)$. By contrast, treatment success in type III achalasia was achieved

Box 2 | Open research questions
- The role of concurrent high-resolution manometry
(HRM) with impedance in the assessment of
oesophageal motility disorders
- The clinical utility of provocative maneuvers, including
multiple repeated swallows, rapid drink challenge
and solid test meals, done in conjunction with HRM
- Expansion of the Chicago Classification to disorders
of the upper oesophageal sphincter, GERD and other
conditions
- Refining the definition of outlet obstruction,
hypercontractility (jackhammer oesophagus) and
ineffective motility disorders on the basis of clinical
outcome studies
- The role of functional lumen impedance planimetry
(FLIP) topography during diagnostic endoscopy as
an adjunct to or replacement for HRM studies


Table 4 | Preferred treatments for achalasia subtypes and achalasia syndromes as defined by CC v3.0

\begin{tabular}{|c|c|c|}
\hline Condition & Preferred treatment & Comment \\
\hline \multicolumn{3}{|c|}{ CC v3.0 achalasia subtypes } \\
\hline Type I achalasia & PD, LHM, POEM & $\begin{array}{l}\text { - All treatments efficacious } \\
\text { - Expect more reflux after POEM, especially } \\
\text { in patients with hiatal hernia }\end{array}$ \\
\hline Type II achalasia & PD & $\begin{array}{l}\text { All treatments are highly efficacious, PD has } \\
\text { least morbidity and lowest cost }\end{array}$ \\
\hline Type III achalasia & POEM & Can calibrate the myotomy to the spastic segment \\
\hline \multicolumn{3}{|c|}{ Achalasia syndromes beyond CC v3.0 } \\
\hline $\begin{array}{l}\text { Oesophagogastric } \\
\text { junction outflow } \\
\text { obstruction }\end{array}$ & $\begin{array}{l}\text {-1st choice: observation } \\
\text { - 2nd choice: calcium-channel blockers } \\
\text { - 3rd choice: botulinum toxin type A }\end{array}$ & $\begin{array}{l}\text { - Many cases resolve spontaneously } \\
\text { - If achalasia therapies are applied, 1st choice } \\
\text { PD, 2nd choice POEM }\end{array}$ \\
\hline $\begin{array}{l}\text { Absent contractility } \\
\text { deemed to be achalasia }\end{array}$ & PD, LHM, POEM & Treat as type I achalasia \\
\hline DES deemed to be achalasia & POEM & Treat as type III achalasia \\
\hline Opioid effect & $\begin{array}{l}\text { - 1st choice: discontinue opioid } \\
\text { - 2nd choice: botulinum toxin type A } \\
\text { - 3rd choice: PD } \\
\text { - 4th choice: POEM }\end{array}$ & $\begin{array}{l}\text { Time course of reversal with opioid cessation } \\
\text { is not known }\end{array}$ \\
\hline Obstruction & $\begin{array}{l}\text { - Conventional dilation } \\
\text { - Operative reversal if relevant } \\
\text { - Directed medical therapy ifrelevant }\end{array}$ & $\begin{array}{l}\text { Many entities mimic achalasia, sometimes } \\
\text { termed 'pseudoachalasia': eosinophilic } \\
\text { oesophagitis, cancer, reflux stricture etc. }\end{array}$ \\
\hline
\end{tabular}

in $40 \%$ and $86 \%$ of patients for pneumatic dilation and LHM respectively, although the difference between the two techniques was not statistically significant because of small patients numbers ( $n=10$ and $n=8$ respectively, $P=0.12$ ). Considering that the cost of pneumatic dilation is substantially less than LHM and that the risk of oesophageal perforation between techniques is comparable (about $1 \%$ when performed by gastroenterologists with extensive experience with the procedures $)^{58}$, these findings argue for pneumatic dilation as the preferred initial treatment for type II achalasia.

\section{POEM}

Coincident with the assimilation of HRM and the CC, the widespread adoption of the POEM procedure was a major development in achalasia therapeutics. The POEM procedure involves making a mucosal incision in the mid-oesophagus and creating a submucosal tunnel to the gastric cardia using a standard endoscope and electrocautery ${ }^{59}$. A circular muscle myotomy is then performed from within the submucosal tunnel, beginning at the gastric cardia and progressing proximally across the LES. Therein lies an important advantage of POEM over LHM: the myotomy performed with POEM can be longer if desired, potentially involving the entire length of smooth muscle oesophagus, whereas LHM is limited to the length of oesophagus that can be safely accessed from below the diaphragm. This benefit is especially relevant in type III achalasia, in which therapy limited to the LES (pneumatic dilation) has worse outcomes (TABLE 3). Supportive of that hypothesis, in a meta-analysis of uncontrolled POEM series, Khan et al. reported a weighted pooled response rate of $92 \%$ (95\% CI 84-96\%) in type III achalasia with a mean length of myotomy of $17.2 \mathrm{~cm}$ (range 13.0$19.7 \mathrm{~cm})^{60}$. Treatments effective for type III achalasia might also prove effective for other spastic disorders also characterized by obstructive physiology of the smooth muscle oesophagus: distal oesophageal spasm and jackhammer oesophagus. The meta-analysis by Khan et al. ${ }^{60}$ also reported a weighted pooled response rate of $72 \%$ (95\% CI 55-83\%) in jackhammer oesophagus and a response rate in distal oesophageal spasm of $88 \%$ (95\% CI $61-97 \%$ ), only $4 \%$ less than in type III achalasia $^{60}$. However, it must be emphasized that these data are from short-term uncontrolled studies, and the appropriate indications for POEM that balance the benefits and risks of the procedure, and the optimal length of myotomy, have yet to be defined. Similarly, the degree to which reflux after POEM is a problem remains to be determined. A randomized controlled trial published in 2017 comparing POEM with pneumatic dilation found the POEM procedure to be more efficacious in terms of therapeutic success, but also more likely to result in post-procedure reflux oesophagitis ${ }^{61}$.

The preceding discussion makes no mention of medical treatments for achalasia, specifically botulinum toxin ${ }^{62-65}$, calcium-channel blockers ${ }^{66}$, nitrates ${ }^{66}$ and phosphodiesterase type 5 inhibitors ${ }^{67}$ primarily because, although these agents provide some symptomatic benefit, they are not durable therapies and they do not halt the disease progression toward oesophageal decompensation characterized by dilatation and food retention. For example, in the case of botulinum toxin injected into the LES, about two-thirds of patients with achalasia report an improvement in dysphagia, 
but most relapse within a year and repeat treatments have diminished effectiveness, making it a poor firstline therapy ${ }^{62-65}$. Nonetheless, these treatments can be useful in patients who are not candidates for definitive therapy because of severe comorbidity. They can also be useful in situations in which one is uncertain whether or not a patient has achalasia, for example in some of the achalasia syndromes detailed in TABLE 2.

Clearly, there are substantial limitations to current knowledge on the optimal treatment of oesophageal motility disorders as we have come to understand them with HRM (BOX 2). Although the CC v3.0 has helped clarify several issues, especially the varied phenotypes of achalasia, it has also led to the realization that there are circumstances beyond type I, II, and III achalasia in which therapies once reserved for achalasia seem appropriate. In these domains, theories regarding the optimal treatment for each entity are many but evidence remains thin ${ }^{68-70}$. Nonetheless, one needs to act on the best evidence available. TABLE 4 details the preferred therapeutic interventions in the opinion of the authors of this Consensus Statement for the achalasia syndromes within and beyond CC v3.0, listed in TABLE 1 and TABLE 2. The suggestions assume that all treatment options are available and affordable, which in reality is rarely the case.

\section{Conclusions}

HRM and analysis algorithms, summarized in the CC v3.0, have led to a major restructuring in the classification of oesophageal motility disorders. The cardinal feature of achalasia, impaired LES relaxation, is now recognized to occur in several disease phenotypes: without peristalsis, with premature (spastic) distal oesophageal contractions, with pan-oesophageal pressurization, or with peristalsis. An immediate effect of this advance has been increased detection of achalasia, challenging previous epidemiological estimates of the incidence and prevalence of this disorder. Furthermore, without a disease-specific biomarker, no manometric pattern is absolutely sensitive or specific for idiopathic achalasia caused by a myenteric plexopathy and physiological testing reveals a number of syndromes, not meeting CC criteria for achalasia, which also benefit from therapies formerly reserved for achalasia. Complementary assessment with FLIP or provocative maneuvers during HRM can be useful in defining these syndromes. The utility of these additional clinical assessment techniques has become particularly relevant with the development of the POEM procedure, a minimally invasive technique for performing a calibrated myotomy of the oesophageal circular muscle. Hence, with HRM and the CC v3.0 we have come to conceptualize oesophageal motility disorders by specific aspects of physiological dysfunction, potentially involving the LES and/or obstructive physiology of the distal smooth muscle oesophagus. A major implication of this approach is a shift in management strategy towards rendering treatment in a phenotypespecific manner; for example, POEM calibrated to patient-specific physiology as defined by HRM for the spastic disorders, and pneumatic dilation for the disorders limited to the LES.
1. Kahrilas, P. J. et al. The Chicago Classification of esophageal motility disorders, v3.0 Neurogastroenterol. Motil. 27, 160-174 (2015).

2. Clouse, R. E. \& Staiano, A. Topography of the esophageal peristaltic pressure wave. Am. J. Physiol. 261, G677-G684 (1991)

3. Clouse, R. E., Staiano, A., Alrakawi, A. \& Haroian, L. Application of topographical methods to clinical esophageal manometry. Am. J. Gastroenterol. 95, 2720-2730 (2000)

4. Gyawali, C. P. High resolution manometry: the Ray Clouse legacy. Neurogastroenterol Motil. 24 (Suppl. 1), 2-4 (2012).

5. Grubel, C., Hiscock, R. \& Hebbard, G. Value of spatiotemporal representation of manometric data. Clin. Gastroenterol. Hepatol. 6, 525-530 (2008).

6. Soudagar, A. S., Sayuk, G. S. \& Gyawali, C. P. Learners favor high resolution esophageal manometry with better diagnostic accuracy over conventional line tracings. Gut 61, 798-803 (2012).

7. Roman, S. et al. High-resolution manometry improves the diagnosis of esophageal motility disorders in patients with dysphagia: a randomized multicenter study. Am. J. Gastroenterol. 111, 372-380 (2016).

8. Carlson, D. A. \& Kahrilas, P. J. How to effectively use high-resolution esophageal manometry. Gastroenterology 151, 789-792 (2016).

9. Yadlapati, R. et al. Benchmarks for the interpretation of esophageal high-resolution manometry. Neurogastroenterol. Motil. 29, e12971 (2017).

10. Yadlapati, R. et al. A system to assess the competency for interpretation of esophageal manometry identifies variation in learning curves. Clin. Gastroenterol. Hepatol. http://dx.doi.org/10.1016/j.cgh.2016.07.024 (2016).

11. Xiao, Y. et al. The effect of a sitting versus supine posture on normative esophageal pressure topography metrics and Chicago Classification diagnosis of esophageal motility disorders. Neurogastroenterol. Motil. 24, e509-e516 (2012).
12. Herregods, T. V., Roman, S., Kahrilas, P. J., Smout, A. J. \& Bredenoord, A. J. Normative values in esophageal high-resolution manometry. Neurogastroenterol. Motil. 27, 175-187 (2015).

13. Ghosh, S. K. et al. Impaired deglutitive EGJ relaxation in clinical esophageal manometry: a quantitative analysis of 400 patients and 75 controls. Am. J. Physiol. 293, G878-G885 (2007).

14. Pandolfino, J. E. et al. Quantifying EGJ morphology and relaxation with high-resolution manometry: a study of 75 asymptomatic volunteers. Am. J. Physiol. Gastrointest. Liver Physiol. 290, G1033-G1040 (2006).

15. Pandolfino, J. E. et al. The contractile deceleration point: an important physiologic landmark on oesophageal pressure topography. Neurogastroenterol. Motil. 22, 395-400 (2010).

16. Pandolfino, J. E. et al. Distal esophageal spasm in high-resolution esophageal pressure topography: defining clinical phenotypes. Gastroenterology 141 , 469-475 (2011).

17. Lin, Z. et al. Localizing the contractile deceleration point (CDP) in patients with abnormal esophageal pressure topography. Neurogastroenterol. Motil. 24 972-975 (2012)

18. Pandolfino, J. E. et al. Achalasia: a new clinically relevant classification by high-resolution manometry. Gastroenterology 135, 1526-1533 (2008).

19. Pandolfino, J. E. \& Kahrilas, P. J. The second American Gastroenterological Association technical review on the clinical use of esophageal manometry. Gastroenterology 128, 209-229 (2005).

20. Spechler, S. J. \& Castell, D. O. Classification of oesophageal motility abnormalities. Gut 49, 145-151 (2001).

21. Salvador, R. et al. The preoperative manometric pattern predicts the outcome of surgical treatment for esophageal achalasia. J. Gastrointest. Surg. 14, 1635-1645 (2010).

22. Pratap, N. et al. Achalasia cardia subtyping by high-resolution manometry predicts the therapeutic outcome of pneumatic balloon dilatation.

J. Neurogastroenterol. Motil. 17, 48-53 (2011).

23. Rohof, W. O. et al. Outcomes of treatment for achalasia depend on manometric subtype. Gastroenterology 144, 718-725 (2013).

24. Kahrilas, P. J. \& Boeckxstaens, G. The spectrum of achalasia: lessons from studies of pathophysiology and high-resolution manometry. Gastroenterology 145, 954-965 (2013).

25. Lin, Z. et al. Refining the criterion for an abnormal integrated relaxation pressure in esophageal pressure topography based on the pattern of esophageal contractility using a classification and regression tree model. Neurogastroenterol. Motil. 24, e356-e363 (2012).

26. Ponds, F. A., Bredenoord, A. J., Kessing, B. F. $\ltimes$ Smout, A. J. Esophagogastric junction distensibility identifies achalasia subgroup with manometrically normal esophagogastric junction relaxation. Neurogastroenterol. Motil. 29, e12908 (2017).

27. Pandolfino, J. E. et al. Distensibility of the esophagogastric junction assessed with the functiona lumen imaging probe (FLIP) in achalasia patients. Neurogastroenterol. Motil. 25, 496-501 (2013).

28. Lin, Z. et al. Flow time through esophagogastric junction derived during high-resolution impedancemanometry studies: a novel parameter for assessing esophageal bolus transit. Am. J. Physiol. 307, G158-G163 (2014).

29. Lin, Z. et al. High-resolution impedance manometry measurement of bolus flow time in achalasia and its correlation with dysphagia. Neurogastroenterol. Motil. 27, 1232-1238 (2015)

30. Fornari, F., Bravi, I., Penagini, R., Tack, J. \& Sifrim, D. Multiple rapid swallowing: a complementary test during standard oesophageal manometry. Neurogastroenterol. Motil. 21, e718-e741 (2009).

31. Ang, D. et al. Rapid Drink Challenge in high-resolution manometry: an adjunctive test for detection of esophageal motility disorders. Neurogastroenterol. Motil. 29, e12902 (2017). 
32. Kahrilas, P. J., Ghosh, S. K. \& Pandolfino, J. E. Esophageal motility disorders in terms of pressure topography: the Chicago Classification. J. Clin. Gastroenterol. 42, 627-635 (2008).

33. Bredenoord, A. J. et al. Chicago classification criteria of esophageal motility disorders defined in high resolution esophageal pressure topography. Neurogastroenterol. Motil. 24, 57-65 (2012)

34. Roman, S. et al. Partial recovery of peristalsis after myotomy for achalasia; more the rule than the exception. JAMA Surg. 148, 157-164 (2013)

35. Hirano, I. et al. Manometric heterogeneity in patients with idiopathic achalasia. Gastroenterology 120 , 789-798 (2001)

36. Mittal, R. K., Ren, J., McCallum, R. W., Shaffer, H. A. Jr $\Sigma$ Sluss, J. Modulation of feline esophageal contractions by bolus volume and outflow obstruction. Am. J. Physiol. 258, G208-G215 (1990).

37. Schneider, J. H., Peters, J. H., Kirkman, E., Bremner, C. G. \& DeMeester, T. R. Are the motility abnormalities of achalasia reversible? An experimental outflow obstruction in the feline model. Surgery 125, 498-503 (1999).

38. Cruiziat, C. et al. High resolution esophageal manometry evaluation in symptomatic patients after gastric banding for morbid obesity. Dig. Liver Dis. 43, 116-120 (2011).

39. Khan, A., Ren-Fielding, C. \& Traube, M. Potentially reversible pseudoachalasia after laparoscopic adjustable gastric banding. J. Clin. Gastroenterol. 45, 775-779 (2011)

40. Goldblum, J. R., Rice, T. W. \& Richter, J. E. Histopathologic features in esophagomyotomy specimens from patients with achalasia. Gastroenterology 111, 648-654 (1996).

41. Sodikoff, J. B. et al. Histopathologic patterns among achalasia subtypes. Neurogastroenterol. Motil. 28, 139-145 (2016)

42. Carlson, D. A. et al. The functional lumen imaging probe detects esophageal contractility not observed with manometry in patients with achalasia. Gastroenterology 149, 1742-1751 (2015).

43. Scherer, J. R., Kwiatek, M. A., Soper, N. J., Pandolfino, J. E. \& Kahrilas, P. J. Functional esophagogastric junction obstruction with intact peristalsis: a heterogeneous syndrome sometimes akin to achalasia. J. Gastrointest. Surg. 13, 2219-2225 (2009).

44. Ratuapli, S. K. et al. Opioid-induced esophageal dysfunction (OIED) in patients on chronic opioids. Am. J. Gastroenterol. 110, 979-984 (2015).

45. Fox, M. R. \& Bredenoord, A. J. Oesophageal high-resolution manometry: moving from research into clinical practice. Gut 57, 405-423 (2008).

46. Wang, Y. T. et al. Investigation of dysphagia after antireflux surgery by high-resolution manometry: impact of multiple water swallows and a solid test meal on diagnosis, management, and clinical outcome. Clin. Gastroenterol. Hepatol. 13, 1575-1583 (2015).

47. Burton, P. R. et al. The effect of laparoscopic adjustable gastric bands on esophageal motility and the gastroesophageal junction: analysis using high-resolution video manometry. Obes. Surg. 19, 905-914 (2009).

48. Van Hoeij, F. B., Smout, A. J. \& Bredenoord, A. J. Characterization of idiopathic esophagogastric junction outflow obstruction. Neurogastroenterol. Motil. 27, 1310-1316 (2015)

49. Pérez-Fernández, M. T., Santander, C., Marinero, A Burgos-Santamaría, D. \& Chavarría-Herbozo, C. Characterization and follow-up of esophagogastric junction outflow obstruction detected by high resolution manometry. Neurogastroenterol. Motil. 28 116-126 (2016).
50. Sweis, R., Anggiansah, A., Wong, T., Brady, G $\&$ Fox, M. Assessment of esophageal dysfunction and symptoms during and after a standardized test meal: development and clinical validation of a new methodology utilizing high-resolution manometry. Neurogastroenterol. Motil. 26, 215-228 (2014).

51. Pandolfino, J. E. \& Gawron, A. J. Achalasia, a systematic review. JAMA. 313, 1841-1852 (2015).

52. Duffield, J. A. et al. Incidence of achalasia in South Australia based on esophageal manometry findings. Clin. Gastroenterol. Hepatol. 15, 360-365 (2017).

53. Samo, S. et al. Incidence and prevalence of achalasia in central Chicago from 2004-2014, since the widespread use of high-resolution manometry. Clin. Gastroenterol. Hepatol. 15, 366-373 (2017).

54. Eckardt, V. F., Hoischen, T. \& Bernhard, G. Life expectancy, complications, and causes of death in patients with achalasia: results of a 33-year follow-up investigation. Eur. J. Gastroenterol. Hepatol. 20 956-960 (2008).

55. Kappelle, W. F., Bogte, A. \& Siersema, P. D. Hydraulic dilation with a shape-measuring balloon in idiopathic achalasia: a feasibility study. Endoscopy 47, 1028-1034 (2015).

56. Boeckxstaens, G. E. et al. Pneumatic dilation versus laparoscopic Heller's myotomy for idiopathic achalasia. N. Engl. J. Med. 364, 1807-1816 (2011).

57. Moonen, A. et al. Long-term results of the European achalasia trial: a multicenter randomised controlled trial comparing pneumatic dilation versus laparoscopic Heller myotomy. Gut 65, 732-739 (2016).

58. Lynch, K. L., Pandolfino, J. E., Howden, C. W. \& Kahrilas, P. J. Major complications of pneumatic dilation and Heller myotomy for achalasia: single center experience and systematic review of the literature. Am. J. Gastroenterol. 107, 1817-1825 (2012).

59. Inoue, H. et al. Per-oral endoscopic myotomy: a series of 500 patients. J. Am. Coll. Surg. 221, 256-264 (2015).

60. Khan, A. K. et al. Is POEM the answer for management of spastic esophageal disorders? A systematic review and meta-analysis. Dig. Dis. Sci. 62, 35-44 (2017).

61. Ponds, F. A. et al. Peroral endoscopic myotomy (POEM) versus pneumatic dilation in therapy-naïve patients with achalasia: results of a randomized controlled trial. Gastroenterology 152, S139 (2017).

62. Pasricha, P. J., Rai, R., Ravich, W. J., Hendrix, T. R. \& Kalloo, A. N. Botulinum toxin for achalasia: long-term outcome and predictors of response. Gastroenterology 110, 1410-1415 (1996).

63. Annese, V. et al. GISMAD Achalasia Study Group. A multicentre randomized study of intrasphincteric botulinum toxin in patients with oesophageal achalasia. Gut 46, 597-600 (2000)

64. Vaezi, M. F. et al. Botulinum toxin versus pneumatic dilatation in the treatment of achalasia: a randomised trial. Gut 44, 231-239 (1999).

65. Zaninotto, G. et al. Randomized controlled trial of botulinum toxin versus laparoscopic Heller myotomy for esophageal achalasia. Ann. Surg. 239, 364-370 (2004).

66. Gelfond, M., Rozen, P. \& Gilat, T. Isosorbide dinitrate and nifedipine treatment of achalasia: a clinical, manometric and radionuclide evaluation. Gastroenterology 83, 963-969 (1982).

67. Bortolotti, M., Mari, C., Lopilato, C., Porrazzo, C. \& Miglioli, M. Effects of sildenafil on esophageal motility of patients with idiopathic achalasia. Gastroenterology 118, 253-257 (2000).

68. Kahrilas, P. J. Treating achalasia; more than just flipping a coin. Gut 65, 726-727 (2016)
69. Ihara, E., Muta, K., Fukaura, K \& Nakamura, K Diagnosis and treatment strategy of achalasia subtypes and esophagogastric outflow obstruction based on highresolution manometry. Digestion 95, 29-35 (2017).

70. Kumbhari, V. et al. Peroral endoscopic myotomy (POEM) versus laparoscopic Heller myotomy (LHM) for the treatment of Type III achalasia in 75 patients: a multicenter comparative study. Endosc. Int. Open 3, E195-E201 (2015).

\section{Acknowledgements:}

The International Working Group for Disorders of Gastrointestinal Motility and Function initiated the consensus meet ings and provided material support for the consensus process. Five separate groups reviewed the current state-ofthe-art in clinical measurement of gastrointestinal motility and function: oropharynx, esophagus, reflux disease, stomach / intestine and anorectum. This process was endorsed by the European Society of Neurogastroenterology and Motility (ESNM) and the European Society of Colo-Proctology (ESCP) with representation and support from the American Neurogastroenterology and Motility Society (ANMS), South and Latin American Neurogastroenterology and Motility Society (SLNG), Asian Neurogastroenterology and Motility Association (ANMA) and members of the Australasian Neurogastroenterology and Motility Association (ANGMA). Financial support was provided by the United European Gastroenterology (UEG) Education Committee, registration fees for meetings and sponsorship from all major manufacturers of physiological measurement equipment. P.J.K. and J.E.P. were supported by R01 DK079902 (J.E.P.) and R01DK56033 (P.J.K.) from the US Public Health Service.

Author contributions:

P.J.K. researched data for the article. All of the authors contributed to discussion of content, wrote the article, and review and/or edited the manuscript before submission.

\section{Competing interests statement}

A.J.B. has received research funding from Given Imaging and MMS, and educational funding from Medical Measurement Systems. M.F. has performed consultancy work and served on the advisory board for Given Imaging, and has received educational funding from Given Imaging, Sandhill Scientific and Medical Measurement Systems. C.P.G. has received educational and research funding from Given Imaging. J.E.P. has performed consultancy work for and received education funding from Given Imaging. S.R. has performed consultancy work for Medtronic and Sandhill Scientific, and has received educational funding from Medtronic and a research grant from Crospon. P.J.K and A.J.P.M.S. declare no competing interests.

\section{Publisher's note}

Springer Nature remains neutral with regard to jurisdictional claims in published maps and institutional affiliations.

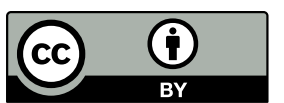

This work is licensed under a Creative Commons Attribution 4.0 International License. The images or other third party material in this article are included in the article's Creative Commons license, unless indicated otherwise in the credit line; if the material is not included under the Creative Commons license, users will need to obtain permission from the license holder to reproduce the material. To view a copy of this license, visit http://creativecommons.org/licenses/by/4.0/.

FURTHER INFORMATION

International Working Group for Disorders of

Gastrointestinal Motility and Function: http://www.idigest.ch/

ALL LINKS ARE ACTIVE IN THE ONLINE PDF 